\title{
Participation in socially-productive activities, reciprocity and wellbeing in later life: baseline results in England
}

\author{
ANNE MGMUNN*, JAMES NAZROO†, \\ MORTEN WAHRENDORF $\ddagger$, ELIZABETH BREEZE* \\ and PAOLA ZANINOTTO*
}

\begin{abstract}
This paper examines whether participation in social activities is associated with higher levels of wellbeing among post-retirement age people in England, and, if so, whether these relationships are explained by the reciprocal nature of these activities. Cross-sectional analysis of relationships between social activities (including paid work, caring and volunteering) and wellbeing (quality of life, life satisfaction and depression) was conducted among participants of one wave of the English Longitudinal Study of Ageing (ELSA) who were of state pension age or older. Participants in paid or voluntary work generally had more favourable wellbeing than those who did not participate in these activities. Caring was not associated with wellbeing, although female carers were less likely to be depressed than noncarers. Carers, volunteers and those in paid work who felt adequately rewarded for their activities had better wellbeing than those who were not participating in those activities, while those who did not feel rewarded did not differ from nonparticipants. These results point to the need to increase the rewards that older people receive from their productive activities, particularly in relation to caring work.
\end{abstract}

KEY WORDS - socially productive activities, wellbeing, reciprocity.

\section{Introduction}

Retirement has historically been perceived as a time of financial and physical decline (Phillipson I990; Townsend i98I) linked with the adverse effects of a loss of financial stability, sense of purpose and social activity derived from employment (Moen 1996). However, increasing life

* Department of Epidemiology and Public Health, University College London.

$\uparrow$ School of Social Sciences, University of Manchester, Manchester, UK.

† Department of Medical Sociology, University of Duesseldorf, Duesseldorf, Germany. 
expectancy (Government Actuaries Department 2002; Hill et al. 1999) and the growing number of people leaving paid employment prior to state pension age (Blundell, Meghir and Smith 2001; Laczko and Phillipson I99I) have contributed to the transformation of retirement for some into a period of health and activity, a period which has been labelled the 'Third Age' (Gilleard and Higgs 2000; Laslett 1996). The experience of growing older is not, of course, homogeneous and there are inequalities in accessing the opportunities represented by the Third Age (Hyde et al. 2004; Mein et al. 2000). The notion of a Third Age is defined, in part, by participation in social activities in late-middle and early-old age. Many studies have shown that participation in social activities is associated with lower levels of disability (Mendes de Leon et al. 200I; Mendes de Leon, Glass and Berkman 2003; Menec 2003), mortality (Glass et al. I999; Lennartsson and Silverstein 2001; Menec 2003) and increased wellbeing in later life (Borgonovi 2008; Glass et al. 2006; Luoh and Herzog 2002; MorrowHowell et al. 2003; Musick, Herzog and House r999). Yet the complex association between activities and health is still relatively unexplored, with studies using homogeneous measures of social activities which are unable to differentiate specific characteristics.

Against this background, some authors have focused on social productivity and the interpersonal exchanges which make up sociallyproductive activities (Siegrist, Knesebeck and Evan Pollack 2004; Wahrendorf, Knesebeck and Siegrist 2006). Siegrist et al. (2004:4) defined social productivity as a 'continued activity that generates goods or services that are socially or economically valued by the recipient(s)', and argued that socially-productive activities are based on the societal norm of reciprocity (Gouldner I960), in which the effort of doing the activity is made in anticipation of an equivalent reward that reflects the value of the effort involved. When an imbalance is perceived between the rewards received in relation to the effort expended, the norm of reciprocity has been broken which, in the long run, elicits strong negative emotions of injustice that influence self-esteem. This theory of effort-reward imbalance was first developed in relation to paid work (Siegrist 1996; Siegrist and Marmot 2004), where the exchange of rewards (money, job security, promotion) for effort (task accomplishment) are set out in formal contracts. A relationship has been shown between effort-reward imbalance at work and cardiovascular disease (Chandola, Siegrist and Marmot 2005; Siegrist 2005; Kivimaki et al. 2002), coronary heart disease (Bosma et al. I998; Kuper et al. 2002), as well as diabetes, depression, alcohol dependence, poor selfrated health (Marmot, Siegrist and Theorell 2006; Schnall et al. 2000; Siegrist 2005), and poor mental health (Pikhart et al. 2004). One previous study (Wahrendorf et al. 2006) examined empirically the relationship 
between participation in socially-productive activities and wellbeing in later life, as well as the importance of reciprocity to these relationships among countries in mainland Europe. It found that participation in socially-productive activities was associated with wellbeing, but that this relationship varied according to the reciprocal nature of the activity. No previous study has examined these relationships in England, and there is evidence to suggest that there are cultural variations in the relationship between participation in socially-productive activities and depression (Kikuzawa 2006). Also, no previous study has focused on these relationships in the post-retirement age population. Participation in sociallyproductive activities is likely to be most salient in the post-retirement age period when people tend to be less involved with the main life activities of paid employment and child rearing. For example, Van Willigen (2000) showed that older volunteers (aged 6o+ years) experienced greater increases in life satisfaction, and improvements in perceived health, as a result of the time they spent volunteering, than younger volunteers.

This study is of participants from one cross-sectional wave in 2004 of the English Longitudinal Study of Ageing (ELSA) who were over the British state pension age to address the following research questions:

I. To what extent are post-retirement age people in England participating in socially-productive activities such as paid work, caring, or volunteering?

2. Does participation in socially-productive activities among the postretirement age population in England vary according to financial circumstances, physical health or marital status?

3. Do people who participate in socially-productive activities postretirement have a higher level of wellbeing than those who do not?

4. Are relationships between participation in socially-productive activities and wellbeing explained by the reciprocal nature of the social relations on which the activities are based?

\section{Methods}

Sample

Participants in the second wave of ELSA who were above the British state pension age (currently 65 years for men and 60 for women) comprise the sample for this study. ELSA is a panel study of men and women who were aged 50 or more years in 2002 and lived in households that had previously responded to the 1998, I999 or 2001 Health Survey for England (HSE), an annual, nationally-representative cross-sectional household 
survey. Wave 2 of ELSA was conducted in 2004 and was chosen for this study because it was the first wave to collect information about the rewards that participants received from caring, volunteering and paid work. Wave 2 achieved an individual response rate of 8I.5 per cent of those eligible from Wave $\mathrm{I}$. This resulted in a sample of 5,384 participants who were post-state pension age at Wave 2. Analyses were weighted for nonresponse bias at Wave I and loss-to-follow-up bias between Waves I and 2. Ethical approval for ELSA was obtained from the London Multi-centre Research Ethics Committee. Further details of the study are available at http://www.ifs.org.uk/elsa/report.htm.

\section{Measures}

Wellbeing outcome measures. This study uses three indicators of wellbeing: quality of life, life satisfaction, and depression. Quality of life was measured using the CASPig, a I9-item scale comprised of four domains: control, autonomy, self-realisation and pleasure, which was specifically developed to measure quality of life at older ages (Hyde et al. 2003). Scores ranged from six to 57 with higher scores indicating better quality of life. Life satisfaction was measured using the five-item version of the Satisfaction with Life Scale (Diener et al. 1985) with scores ranging from five to 35 and higher scores reflecting more life satisfaction. Quality of life and life satisfaction were both used as continuous measures in this study. Depression was measured using the eight-item version of the Center for Epidemiologic Studies Depression Scale (CES-D). The CES-D asks the degree to which participants experienced depressive symptoms, such as restless sleep and being unhappy, over the past month and has been extensively used in various clinical and non-clinical settings with diverse populations. Cut-offs of three, four or five items have been suggested when using the eight-item CES-D (Steffick 200o). In this study, a dichotomous categorical measure of depression is used, defined by reporting four or more items on the CES-D.

Socially-productive activities. Three types of socially-productive activity are distinguished in this study: caring for someone, voluntary work, and paid work. Respondents were asked whether or not they did any of these activities during the last month. Indicators of the reciprocal nature of each of these activities were measured. Participants who reported caring for someone or volunteering in the past month were asked the following: 'Considering all the efforts that I have put into my [activity], I have always received adequate appreciation from others'. Response categories were 'strongly agree', 'agree', 'disagree', and 'strongly disagree'. Participants 
who 'disagreed' or 'strongly disagreed' with this statement were considered to feel not adequately rewarded for their caring or volunteering activity because an imbalance was perceived between the costs and gains of their participation (Wahrendorf et al. 2006). In relation to paid work, an effortreward scale was created using two items that measured 'effort' and five items that assessed 'reward' in relation to the participant's paid job (if they reported one). The scale was defined by a ratio of the sum of effort items to the sum of reward items adjusted for the different number of items assessing reward and effort (range $0.25-3.33$, median o.88). Tertiles of the ratio were used in this study. Additional analyses in relation to caring took account of who the carer's main care recipient was, as well as the number of care recipients the carers reported helping during the past week. These items were only asked of participants who reported caring for someone during the past week.

Predictors of participation in socially-productive activities. Certain factors were hypothesised as predicting participation in socially-productive activities. These were gender, age, wealth, health and partnership status. Age in fiveyear age groups was used in the descriptive analyses and entered as a continuous variable in the multi-variate models. A measure of household wealth was used which included housing, financial and physical wealth. Wealth was examined in quintiles. Health was measured using self-reports of long-standing illness: the respondents were asked whether they had any long-standing illness, disability or infirmity that had troubled them over a specified period or that was likely to affect them over a stated period. Partnership status was dichotomised into those married or living with a partner and those who were not.

\section{Analysis}

The analysis began by examining rates of participation in sociallyproductive activities in men and women overall, and by age, wealth, health and partnership status. Following this, unadjusted mean quality of life and life satisfaction scores and the proportion who were depressed were examined by participation in activities, separately for men and women. Next, these relationships were modelled separately for men and women for each activity using standard linear regression in relation to quality of life and life satisfaction, and logistic regression in the case of depression. For each activity separately, the regressions were first adjusted for age and then further adjusted for wealth, health and partnership status. These fully-adjusted models were then run separately for each activity, dividing activity participants by reward status (those reporting adequate 
T A B L E I. Participation in socially-productive activities among men aged 65 or more years and women aged 60 or more years

\begin{tabular}{|c|c|c|c|c|c|c|}
\hline \multirow[b]{2}{*}{ Variable and category } & \multicolumn{3}{|c|}{$\operatorname{Men}(n=2,022)$} & \multicolumn{3}{|c|}{ Women $(n=3,362)$} \\
\hline & $\begin{array}{c}\text { Paid } \\
\text { work } \\
\%\end{array}$ & $\begin{array}{c}\text { Caring } \\
\%\end{array}$ & $\begin{array}{c}\text { Volunteering } \\
\%\end{array}$ & $\begin{array}{c}\text { Paid } \\
\text { work } \\
\%\end{array}$ & $\begin{array}{c}\text { Caring } \\
\%\end{array}$ & $\begin{array}{c}\text { Volunteering } \\
\%\end{array}$ \\
\hline \multicolumn{7}{|l|}{ Age (years) } \\
\hline $6 \mathrm{o}-64 \dagger$ (women) & $\mathrm{n} / \mathrm{a}$ & $\mathrm{n} / \mathrm{a}$ & $\mathrm{n} / \mathrm{a}$ & 30.6 & 20.4 & І6.9 \\
\hline $65^{-69 \dagger}(\mathrm{men})$ & I8.3 & II. 8 & $\mathrm{I} 3.8$ & I 2.6 *** & 18.3 & $19 \cdot 3$ \\
\hline $70^{-}-74$ & $9 \cdot 3^{* * *}$ & I0.5 & I $4 \cdot 3$ & $4.7^{* * *}$ & I5. $7^{*}$ & 17.0 \\
\hline $75^{-79}$ & $5 \cdot 4^{* * *}$ & II. 3 & 10.4 & I. $3^{* * *}$ & 10. $7^{* * *}$ & I5.3 \\
\hline $80+$ & $0.9^{* * * *}$ & $4.2^{* * * *}$ & $7 \cdot 5^{* *}$ & $0.8^{* * * *}$ & $4 \cdot 4^{* * * *}$ & $5 \cdot 9^{* * *}$ \\
\hline \multicolumn{7}{|l|}{ Household wealth } \\
\hline Richest quintile $\dagger$ & I5.5 & I2.7 & $24 \cdot 3$ & 17.5 & I9.0 & $27 . \mathrm{I}$ \\
\hline 2nd & II. 2 & 10.2 & 15.6 ** & $\mathrm{I} 3.5$ & I 4.9 & $18.4^{* * *}$ \\
\hline 3 rd & $8.4^{* *}$ & $9 \cdot 9$ & II. 6 **** & I0.9** & I3. $6^{*}$ & I3. $6^{* * *}$ \\
\hline $4^{\text {th }}$ & $6.8^{* * *}$ & I0.3 & $5.6^{* * *}$ & 8.I*** & I $6.3^{*}$ & I0. $4^{* * * *}$ \\
\hline Poorest quintile & $5 \cdot 5^{* * *}$ & $6.7^{* *}$ & $5 \cdot 1^{* * *}$ & $4.8^{* * *}$ & IO.0*** & $7 \cdot 9^{* * *}$ \\
\hline \multicolumn{7}{|l|}{ Long-standing illness } \\
\hline Not ill $\dagger$ & I3.9 & I0.0 & I3.7 & I5.0 & I5.8 & I8.4 \\
\hline Ill & $6.8^{* * *}$ & $9 \cdot 5$ & $10.7^{*}$ & $7.7^{* * *}$ & $\mathrm{I} 2.5^{* *}$ & I $2 . I^{* * * *}$ \\
\hline \multicolumn{7}{|l|}{ Partnership } \\
\hline Living with a partner $\dagger$ & 10.2 & II. 8 & I3.0 & I3.9 & I9.0 & I6.0 \\
\hline Not living with a partner & 8.4 & $6 . \mathrm{I}^{* * *}$ & $9 \cdot 9^{*}$ & $7.6^{* * *}$ & $9 \cdot 3^{* * *}$ & I $3 \cdot 4^{*}$ \\
\hline Total & $9 \cdot 5$ & $9 \cdot 7$ & II.9 & I0.4 & I3.7 & I 4.5 \\
\hline
\end{tabular}

Notes: $\dagger$ Reference group. The significance tests are for differences in participation by age, wealth, health and partnership status within gender and did not test for gender differences in participation.

Significance levels: $* p<0.05, * * p<0.01, * * * p<0.001$.

appreciation and those reporting inadequate appreciation for caring and volunteering, and effort-reward tertiles for paid work). Men and women were combined for these reciprocity models because there were insufficient people reporting inadequate appreciation for a stratified analysis. Finally, cross-tabulations and mean wellbeing scores by care recipients were calculated to explore the nature of caring in further detail.

\section{Results}

Participation in socially-productive activities post-retirement age

Table I shows levels of participation in each of the socially-productive activities for both men and women by age, wealth, health and partnership status. The significance tests were for differences in participation by age, wealth, health and partnership status within gender and did not test for gender differences in participation. Overall, there were no gender 
differences in participation in paid work post-retirement age, with 9.5 per cent of men and Io.4 per cent women having been in paid work during the past month. This arose from the inclusion of women aged 6o-64, as participation in paid work declined dramatically with age, and more so for women than for men, so that among those aged 65 and over, men were more likely than women to be in paid work. Women were more likely than men to have cared for someone or volunteered in the past month, at I3.7 per cent and I4.5 per cent respectively for women, compared with 9.7 per cent and II.9 per cent respectively for men. Participation in sociallyproductive activities generally declined with age, but for many not until the late seventies (as with volunteering for men) or eighties (as with volunteering for women and caring for men).

Participation in socially-productive activities increased with greater wealth for both men and women, and ill men and women were less likely than well men and women to be in paid employment or to be volunteering. Ill and well men were equally likely to have cared for someone during the past month (Table I). Men and women living with a partner were more likely than other men and women to participate in each of the activities, although this difference was not statistically significant among men for paid work. A little over half $(52.5 \%)$ of those who participated in socially-productive activities participated in more than one (not shown). There were no large gender differences in the combinations of activities. Women were a little more likely to combine multiple activities $(56.3 \%)$ compared to men $(46.3 \%)$.

\section{Participation in socially productive activities and wellbeing post-retirement age}

Overall, the mean quality of life score was 42 .I for men and 42.4 for women, and the mean life satisfaction score was 27.0 for men and 26.3 for women, while I2.3 per cent of men and 20.I per cent of women were depressed using the $4+$ cut-off on the CES-D (not shown). Table 2 shows the unadjusted mean quality of life and life satisfaction scores, as well as the prevalence of depression, by participation in socially-productive activities. People who were in paid work, or were volunteering were less likely to be depressed, and had higher mean quality of life and life satisfaction scores than those who were not participating in these activities, with the exception that there was no relationship between paid work and life satisfaction among women. Caring for someone in the past month, however, was not associated with quality of life or life satisfaction. Women who had cared for someone in the past month were less likely to be depressed than noncarers (this difference was not significant for men). The quality of life and life satisfaction scores also increased significantly with an increasing 
T A B L E 2. Unadjusted mean wellbeing scores and prevalence of depression by activities among men aged 65 or more years and women aged 60 or more years

\begin{tabular}{|c|c|c|c|c|c|c|}
\hline \multirow{2}{*}{$\begin{array}{l}\text { Activities } \\
\text { Men aged } 65+\end{array}$} & \multicolumn{2}{|c|}{ Quality of life } & \multicolumn{2}{|c|}{ Life satisfaction } & \multicolumn{2}{|c|}{ Depression } \\
\hline & $\mathcal{N}=\mathrm{I}, 477$ & Mean & $\mathcal{N}=\mathrm{I}, 64 \mathrm{I}$ & Mean & $\mathcal{N}=\mathrm{I}, 94^{2}$ & $\%$ \\
\hline In paid work & I50 & 45.8 & I64 & 28.5 & I85 & 6.5 \\
\hline Not in paid work & $\mathrm{I}, 327$ & $41.7 * * *$ & $\mathrm{I}, 477$ & $26.9 * * *$ & $\mathrm{I}, 757$ & 12.9* \\
\hline Caring & I6I & 42.0 & I73 & 26.8 & I94 & 8.7 \\
\hline Not caring & I, 316 & 42.1 & $\mathrm{I}, 468$ & $27 . I$ & $\mathrm{I}, 74^{8}$ & I2.6 \\
\hline Volunteering & 204 & 45.0 & 220 & 27.9 & 237 & 4.6 \\
\hline Not volunteering & $\mathrm{I}, 273$ & $4^{\mathrm{I} .} 6^{* * * *}$ & $\mathrm{I}, 42 \mathrm{I}$ & $26.9^{*}$ & $\mathrm{I}, 705$ & $\mathrm{I} 3 \cdot 3^{* * * *}$ \\
\hline Women aged $60+$ & $\mathcal{N}=2,36 \mathrm{I}$ & Mean & $\mathcal{N}=2,667$ & Mean & $\mathcal{N}=3,253$ & $\%$ \\
\hline In paid work & 306 & $45 \cdot 5$ & $3^{2 \mathrm{I}}$ & 26.8 & 347 & II. 2 \\
\hline Not in paid work & 2,055 & $42.0^{* * * *}$ & 2,346 & 26.3 & 2,906 & $2 \mathrm{I} . \mathrm{I} * * *$ \\
\hline Caring & 376 & 43.2 & 408 & 26.3 & $45^{\mathrm{I}}$ & 13.7 \\
\hline Not caring & I,985 & 42.3 & 2,259 & 26.3 & 2,802 & $21 . I^{* * *}$ \\
\hline Volunteering & $4 \mathrm{I} 5$ & 45.6 & 446 & 27.3 & 484 & $9 \cdot 5$ \\
\hline Not volunteering & I,946 & $41.8^{* * * *}$ & $2,22 \mathrm{I}$ & $26 . I * * *$ & 2,769 & $22.0^{* * *}$ \\
\hline
\end{tabular}

Significance levels: $* p<0.05, * * * p<0.001$.

number of activities, while the prevalence of depression significantly decreased with an increasing number of activities (not shown).

Table 3 shows the relationship between each of the activities (separately) and each of the wellbeing outcomes for men and women, first adjusted only for age, and then further adjusted for household wealth, longstanding illness and partnership status. Regression coefficients (and 95 per cent confidence intervals) are shown for the quality of life and life satisfaction scores, while odd ratios (and 95 per cent confidence intervals) are shown for depression. In the age-adjusted analysis, participation in each of the activities was associated with increased quality of life and life satisfaction or decreased likelihood of being depressed, with two exceptions. The first exception was caring, which associated with a decreased likelihood of being depressed for women, but was otherwise not associated with the wellbeing outcomes. The second exception was paid work, which was not associated with life satisfaction for women.

In fully-adjusted models, the relationship between paid work and quality of life among women was attenuated (the regression coefficient decreased by 59 per cent and became non-significant), as was the relationship between paid work and depression for both men and women (where the odds ratios for being depressed increased by $3^{6}$ per cent for men and 2I per cent for women and became non-significant for both) (Table 3). Stepwise models showed that this attenuation arose mostly from 
T A B L E 3. Wellbeing by activities among men aged 65 or more years and women aged 60 or more years

\begin{tabular}{|c|c|c|c|c|c|c|c|c|c|}
\hline \multirow{2}{*}{$\begin{array}{l}\text { Activities } \\
\text { Men } \\
\text { aged } 65+\end{array}$} & \multicolumn{3}{|c|}{ Quality of life (regression coefficients) ${ }^{1}$} & \multicolumn{3}{|c|}{ Life satisfaction (regression coefficients) ${ }^{1}$} & \multicolumn{3}{|c|}{ Depression (odds ratios) ${ }^{1}$} \\
\hline & $\begin{array}{l}\mathcal{N}= \\
\mathrm{I}, 454\end{array}$ & Age-adjusted & Fully-adjusted ${ }^{2}$ & $\begin{array}{c}\mathcal{N}= \\
\text { I,6I6 }\end{array}$ & Age-adjusted & Fully-adjusted $^{2}$ & $\begin{array}{l}\mathcal{N}= \\
\mathrm{I}, 976\end{array}$ & Age-adjusted & Fully-adjusted $^{2}$ \\
\hline Paid work & I44 & & & & & & 183 & $0.53(0.28,0.99)$ & $0.72\left(0.3^{8}, \mathrm{I} .37\right)$ \\
\hline Caring & $15^{8}$ & $-0.54(-\mathrm{I} .94,0.87)$ & $-0.89(-2.19,0.4 \mathrm{I})$ & I $7 \mathrm{I}$ & $-0.30(-\mathrm{I} .2 \mathrm{I}, 0.62)$ & $-0.67(-\mathrm{I} .55,0.20)$ & 200 & $0.72(0.43, \mathrm{I} .20)$ & $0.83(0.49, \mathrm{I} .4 \mathrm{I})$ \\
\hline Volunteering & 200 & $3.04(\mathrm{I} .78,4.3 \mathrm{I})$ & I.79 (o.6o, 2.98) & 215 & I.03 $(0.20$, I.85) & $0.36(-0.45$, I.I 6$)$ & $26 \mathrm{I}$ & $0.34(0.18,0.63)$ & $0.43(0.22,0.80)$ \\
\hline $\begin{array}{l}\text { Women } \\
\text { aged } 60+\end{array}$ & $\begin{array}{c}\mathcal{N}= \\
2,335\end{array}$ & Age-adjusted & Fully-adjusted $^{2}$ & $\begin{array}{c}\mathcal{N}= \\
2,640\end{array}$ & Age-adjusted & Fully-adjusted $^{2}$ & $\begin{array}{c}\mathcal{N}= \\
3,306\end{array}$ & Age-adjusted & Fully-adjusted $^{2}$ \\
\hline Paid work & 300 & $.04(0.92,3.15)$ & $0.84(-0.22$, I.90 $)$ & 316 & $0.43(-0.33$, I.I 8$)$ & $-0.06(-0.79,0.68)$ & 375 & $0.58(0.40,0.82)$ & $0.70($ o.48, I.0I $)$ \\
\hline Caring & 373 & $0.05(-0.93$, I.02 $)$ & $-0.35\left(-\mathrm{I} .27,0.5^{8}\right)$ & 405 & $-0.13(-0.78,0.53)$ & $-0.5^{2}(-\mathrm{I} . \mathrm{I} 5,0 . \mathrm{I} 2)$ & 482 & $0.65(0.49,0.87)$ & $0.73(0.54,0.98)$ \\
\hline Volunteering & 408 & $3.39(2.47,4.30)$ & $2.5^{8}($ I. $.70,3.46)$ & 439 & I.05 (0.42, I.68) & $0.65(0.04$, I.26) & 528 & $0.40(0.29,0.55)$ & $0.47(0.34,0.65)$ \\
\hline
\end{tabular}

Notes: I. All comparisons are with those not participating in the activity. All models are run separately for each activity. 2. Further adjusted for long-standing illness, household wealth, living with a partner. 
$\mathrm{T}$ A B L E 4. Wellbeing by rewards from caring, volunteering and paid work among men aged 65 or more years and women aged 60 or more years

\begin{tabular}{|c|c|c|c|c|c|}
\hline Activity rewards & $\mathcal{N}$ & $\begin{array}{l}\text { Quality of life } \\
\text { regression } \\
\text { coefficients }\end{array}$ & $\begin{array}{l}\text { Life satisfaction } \\
\text { regression } \\
\text { coefficients }^{1}\end{array}$ & $\mathcal{N}$ & $\begin{array}{l}\text { Depression } \\
\text { odds ratios }{ }^{1}\end{array}$ \\
\hline $\begin{array}{l}\text { Not caring } \\
\text { Caring - not appreciated } \\
\text { Caring - appreciated }\end{array}$ & $\begin{array}{r}4,74 \mathrm{I} \\
6 \mathrm{o} \\
584\end{array}$ & $\begin{array}{c}0 \\
-3.05(-5.37,-0.72) \\
-0.26(-\mathrm{r} .04,0.53)\end{array}$ & $\begin{array}{c}\mathrm{o} \\
-\mathrm{I} .8 \mathrm{o}(-3.4 \mathrm{I},-\mathrm{o} . \mathrm{I} 9) \\
-\mathrm{o.4}(-0.94, \text { o.I } 3)\end{array}$ & $\begin{array}{r}4,509 \\
64 \\
600\end{array}$ & $\begin{array}{c}\text { I.00 } \\
\text { I.40 (0.75, } 2.58) \\
0.68(0.51,0.90)\end{array}$ \\
\hline $\begin{array}{l}\text { Not volunteering } \\
\text { Volunteering } \\
\text { - not appreciated } \\
\text { - appreciated }\end{array}$ & $\begin{array}{r}\text { III } \\
9^{86}\end{array}$ & $\begin{array}{l}0.96\left(-0.56,2.9^{8}\right) \\
2.35(\text { I. } 75,2.95)\end{array}$ & $\begin{array}{c}-0.45(-\mathrm{I} .47,0.57) \\
\quad 0.59 \text { (o.18, I.0I })\end{array}$ & $\begin{array}{r}\mathrm{I} 45 \\
\mathrm{I}, 237\end{array}$ & $\begin{array}{l}0.44(0.23,0.87) \\
0.64(0.52,0.79)\end{array}$ \\
\hline $\begin{array}{l}\text { Not working } \\
\text { Effort-reward ratio } \\
\text { - worst tertile } \\
\text { - middle tertile } \\
\text { - best tertile }\end{array}$ & $\begin{array}{r}\mathrm{I} 35 \\
\mathrm{I} 08 \\
\mathrm{I} 2 \mathrm{I}\end{array}$ & $\begin{array}{l}0.36(-\mathrm{I} . \mathrm{IO}, \mathrm{I} .82) \\
2.20(\mathrm{o} .6 \mathrm{I}, 3.79) \\
2.06(0.53,3.58)\end{array}$ & $\begin{array}{c}-0.59(-\mathrm{I} .59,0.42) \\
\text { I. } .34(0.23,2.45) \\
0.73(-0.33, \mathrm{I} .80)\end{array}$ & $\begin{array}{l}\text { I } 43 \\
\text { II } 3 \\
\text { I } 32\end{array}$ & $\begin{array}{l}0.83(0.48, \text { I. } 43) \\
0.50(0.24, \text { I.07) } \\
0.3^{2}(0.13,0.77)\end{array}$ \\
\hline
\end{tabular}

Notes: I. Adjusted for age, sex, long-standing illness, household wealth, living with a partner.

the inclusion of illness, but also to the inclusion of wealth. Partnership status did not influence relationships between paid work and wellbeing (i.e. quality of life for women and depression for men and women) (not shown). The relationships between volunteering and the wellbeing outcomes was also attenuated somewhat in the fully-adjusted models, although more so for men than for women, and more so in relation to life satisfaction than for quality of life or depression. For example, the regression coefficient for volunteering and life satisfaction among men decreased by 65 per cent and became non-significant (Table 3). This attenuation was entirely explained by wealth (not shown).

\section{Reciprocity, socially-productive activities and wellbeing post-retirement age}

Table 4 examines the importance of reciprocity in relationships between participation in activities and wellbeing after retirement age. While caring was generally not associated with any of the wellbeing outcomes (with the exception of depression for women), Table 4 shows that carers who did not feel appreciated (for their caring) had significantly worse quality of life and life satisfaction scores compared with non-carers, while carers who felt appreciated were less likely to be depressed than non-carers. Similarly, volunteers who felt appreciated (for their volunteering) had higher quality of life and life satisfaction scores than non-volunteers. Volunteers who did not feel appreciated did not differ significantly from non-volunteers in terms of quality of life and life satisfaction, although unappreciated volunteers had a higher quality of life score than non-volunteers prior to 
T A B L E 5. Main care recipient of those who cared for someone in the past week

\begin{tabular}{|c|c|c|c|c|c|}
\hline Main care recipient & Partner & Child & Grandchild & $\begin{array}{c}\text { Parent or } \\
\text { parent-in-law }\end{array}$ & Other ${ }^{1}$ \\
\hline$\%$ of male carers & 54.I & $4 \cdot 4$ & 8.8 & $\mathrm{I} 3.2$ & 19.5 \\
\hline$\%$ of female carers & 36.3 & 7.2 & 15.5 & 17.2 & 23.8 \\
\hline$\%$ reporting not appreciated & II. 2 & I 2.9 & 2.9 & I3.3 & $4 \cdot 3$ \\
\hline Mean quality of life & 39.0 & $42 . \mathrm{I}$ & $44 \cdot 4$ & 44.0 & $45 \cdot 9$ \\
\hline Mean life satisfaction & 25.4 & 26.2 & 27.0 & 26.3 & $27 \cdot 3$ \\
\hline$\%$ depressed & 20.7 & 12.7 & 2.9 & 8.4 & 7.9 \\
\hline
\end{tabular}

Note: I. Usually friend, neighbour or other relative.

adjusting for wealth (not shown). Table 4 shows that all volunteers were less likely to be depressed than non-volunteers regardless of whether or not they felt appreciated for their volunteering. Regarding employment, Table 4 shows that participants whose jobs were in the best two tertiles of effort-reward balance had significantly better quality of life scores than those not in paid work, and that participants whose jobs were in the middle tertile of effort reward had significantly better life satisfaction scores than those not in paid work. Those in the best effort-reward tertile only had significantly better life satisfaction scores than those not in paid work prior to adjustment for wealth and health (not shown). Participants whose jobs were in the best tertile of effort-reward balance were significantly less likely to be depressed than those who were not in paid work. Participants whose jobs were in the middle effort-reward tertile were only significantly less likely to be depressed than those who were not in paid work prior to adjustment for wealth, health and partnership combined (not shown). The wellbeing of participants whose jobs were in the worst quintile of effort-reward did not differ significantly from that of participants who were not in paid work.

As reciprocity in caring emerged as significantly related to wellbeing in later life, we investigated further the nature of caring in our sample of post-retirement aged English people. Table 5 shows that the main care recipient for male carers was significantly more likely to be their partner than for female carers (54.I \% for men compared with $36.3 \%$ for women), and that carers whose main care recipient was their partner, their child, or their parent or parent-in-law were significantly more likely to report not feeling appreciated for their caring than carers whose main care recipient was a grandchild, friend, neighbour or other relative. Carers whose main care recipient was their partner were significantly more likely to be depressed, and had a significantly lower mean quality of life $(p<$ o.oor $)$ and mean life satisfaction score $(p=0.009)$ than other carers. There were no 
differences in quality of life or life satisfaction score by number of care recipients during the past week (not shown).

\section{Discussion}

This study has shown the importance of considering the quality of the activities in which people are encouraged to participate post-retirement particularly the quality of the experience of caring - as well as the need to consider caring separately from other forms of socially-productive activities in later life. We first examined levels of participation in the postretirement age English population and found that about IO-I5 per cent of people were engaged in paid work, caring or volunteering. Women were a little more likely than men to have cared for someone or volunteered in the past month. Similar analysis in the Survey of Health, Aging and Retirement in Europe (SHARE) found the same gender differences for caring, but that men were more likely than women to have volunteered in the past month (Wahrendorf et al. 2006). Participation in socially-productive activities declined with age, but often not until participants were in their late seventies or eighties, providing some evidence for the existence of a third-age life course period. However, opportunity to participate was structured by wealth, and somewhat by illness, suggesting inequality in access to these third-age activities. This is in line with results from a sample of men aged $5 \mathrm{I}^{-} 70$ years which showed that both socio-economic factors and health status influenced social engagement (Harewood, Pound and Ebrahim 2000).

Participation in paid work or volunteering were each associated with wellbeing outcomes for both men and women, although among women relationships between paid work and wellbeing were attenuated by age, health and, to a lesser extent wealth, while among men the relationship between paid work and depression was explained by health and, to a lesser extent, wealth. Also among men, relationships between life satisfaction and volunteering were attenuated by wealth. Many previous studies have focused specifically on the relationship between volunteering and wellbeing in later life and have shown voluntary work to be associated with favourable wellbeing (Borgonovi 2008; Morrow-Howell et al. 2003; Thoits and Hewitt 200I; Van Willigen 2000; Luoh and Herzog 2002). Volunteering was positively associated with mental health and selfreported health over 12 years of follow-up in the Wisconsin Longitudinal Study (Piliavin and Siegl 2007) and Meier and Stutzer (2008) showed that volunteering led to increased life satisfaction in a large panel study in Germany. In addition, Menec (2003) showed that participation in 
activities was associated with happiness, but not life satisfaction, after sixyears of follow-up, although that study used a check-list of I8 activities which included visiting family and solitary hobbies.

Unlike the other social activities examined here, caring was generally not significantly associated with wellbeing, although female carers were less likely to be depressed than women who had not cared for someone in the past month. Conversely, Hirst (2005) has shown from the British Household Panel Study that carers had worse mental health (using the General Health Questionnaire) than non-carers, more so for women than men. When carers in this study were divided between those who felt appreciated for their caring and those who did not, however, caring became significantly associated with each of the wellbeing outcomes. The emergence of a significant relationship between caring and wellbeing after the inclusion of appreciation lends support to Siegrist's observations on the importance of reciprocal exchange in social relations for health and wellbeing in later life (Siegrist et al. 2004). It also suggests the importance of examining the nature of activities in addition to participation per se. Like Hirst (2005) who found that mental health was particularly poor for those looking after a partner or sick or disabled child, this study found that those looking after a partner or child were significantly more likely to be depressed and to have a worse quality of life and less life satisfaction than other carers.

This study has also shown that, as with caring, volunteers who reported feeling appreciated had significantly better wellbeing than non-volunteers, while volunteers who did not report feeling appreciated did not differ from non-volunteers after adjusting for wealth. This suggests that volunteers are generally better off than non-volunteers, because they are generally wealthier than non-volunteers; once the wealth differences between volunteers and non-volunteers were made equal, the importance of the reciprocal nature of volunteering exchanges for wellbeing emerged. The results of our study are broadly in line with those of Wahrendorf et al. (2006), who examined the relationship between reciprocity in caring and volunteering and wellbeing in mainland Europe. They found that volunteers who reported being appreciated had better quality of life and less depression than non-volunteers, while volunteers who reported no appreciation did not. However, while we found reciprocity to be most important for caring, the previous study found that appreciation from caring was significantly associated with quality of life, but that carers were more likely to be depressed than non-carers regardless of appreciation. The wording of questions about caring, however, did differ in the two studies in important ways.

While this study has shown that continuing to work after state-pension age was associated with positive wellbeing for men, there is likely to be 
significant variation within the group who continued working poststate-pension age. Qualitative reports from people who work past statepension age suggest that the contrasting opportunities associated with the financial resources and occupational identity as a 'worker', as opposed to a 'professional' or 'creative' person and their different pathways to retirement are likely to be related to wellbeing (Hyde et al. 2004; Parry and Taylor 2007). Results from an Australian panel study also suggest that control over the retirement process is more closely associated with wellbeing outcomes than the timing or manner of retirement (De Vaus et al. 2007). The relationship we have seen between effort-reward imbalance at work and wellbeing among post-pension age people is in line with earlier studies of those of working age and mental health (Pikhart et al. 2004; Stansfeld et al. I999) and poor reported health (Niedhammer et al. 2004; Stansfeld et al. I998), and was evident despite the likelihood that those in poor quality jobs will already have removed themselves from the work-force by the age of 65 (Ekerdt and DeViney 1993; Mein et al. 2000; Seigrist et al. 2006).

The main limitation of this study is its cross-sectional design, which makes it impossible to draw conclusions about the causal direction of the relationships. Cause and effect between participation in activities and wellbeing may run in either direction. Prospective studies have established a relationship between failed reciprocity at work and poor health outcomes (Marmot, Siegrist and Theorell 2006), but longitudinal information about reciprocity in relation to other socially-productive activities and wellbeing in later life is only beginning to be collected. This study presents baseline relationships and suggests directions for future research as longitudinal data become available. A second limitation is that all data in the study were self-reported. The relationship between reported rewards from activities and wellbeing may be the result of common variance attributable to reporting bias or negative affect (Burke, Brief and George I993; Chen and Spector 199I). A meta-analysis by Thoresen et al. (2003) suggested that affect was significantly related to a wide variety of job-related attitudes, several studies have now shown that negative affect does not account for relationships between job stressors and self-reported strains (Hoge and Bussing 2004; Spector, Chen and O'Connell 2000; Chen and Spector I99I). Santed et al. (2003) showed that, while negative affect was independently associated with both reported stress and self-reported health, it did not significantly moderate, or inflate, relationships between the two.

Heterogeneity in the relationships seen here between different sociallyproductive activities and wellbeing suggests the need to consider relationships between activities and wellbeing separately. Certain activities, such as volunteering, may comprise a greater element of agency than other activities such as caring. Siegrist et al.'s (2004) definition of 
socially-productive activities includes a voluntary, consensual nature of the activity 'irrespective of its degree of formalization or institutionalization' (2004: 4), excluding activities based on coercion. However, social expectations in relation to the take up of activities make the line between consent and coercion ambiguous, and social expectations are stronger for certain activities, such as caring for a partner, than for others. In turn, these expectations vary by gender, age, class and culture. In addition, caring for people in one's immediate family (that Lynch (2007) called 'primary care relations'), as was the case for most of the carers in this study, involves affective labour characterised by mutual dependence. This may make caring activities more contingent on the maintenance of reciprocity in its relations than is the case with less affective and therefore less mutually dependent activities.

From a policy perspective, the results of the study point to the need to increase the rewards that older people receive from their sociallyproductive activities. In particular, support for carers, but also increasing the quality of the paid jobs and volunteering opportunities available to older people, will ultimately have a positive impact on the growing number of post-retirement age people. Our results also point to the need to differentiate the various socially-productive activities and to raise understanding of the socially-structured variation in the agency inherent in the uptake of socially-productive activities.

\section{Acknowledgements}

The authors are grateful to the UK Economic and Social Research Council (ESRC), whose funding of the project 'Inequalities in health in an ageing population: patterns, causes and consequences' (RES-ooo-23-0590) supported the work on this paper. The ESRC played no role in the design, execution, analysis or interpretation of data, or writing this study. ELSA was developed by a team of researchers based at University College London, the National Centre for Social Research and the Institute for Fiscal Studies. The data were collected by the National Centre for Social Research. The funding is provided by the National Institute of Aging in the United States, and a consortium of UK Government departments co-ordinated by the Office for National Statistics. The developers and funders of ELSA do not bear any responsibility for the analyses or interpretations presented here.

\section{References}

Blundell, R., Meghir, C. and Smith, S. 200I. Pension Incentives and the Pattern of Retirement. Institute for Fiscal Studies, London.

Borgonovi, F. 2008. Doing well by doing good: the relationship between formal volunteering and self-reported health and happiness. Social Science and Medicine, 66, 232 I-34. 
Bosma, H., Peter, R., Siegrist, J. and Marmot, M. i998. Two alternative job stress models and the risk of coronary heart disease. American Fournal of Public Health, 88, 68-74.

Burke, M. J., Brief, A. P. and George, J. M. 1993. The role of negative affectivity in understanding relations between self-reports of stressors and strains: a comment on the applied psychology literature. Fournal of Applied Psychology, 78, 3, 402-12.

Chandola, T., Siegrist, J. and Marmot, M. 2005. Do changes in effort-reward imbalance at work contribute to an explanation of the social gradient in angina? Occupational and Environmental Medicine, 62, 223-30.

Chen, P. Y. and Spector, P. E. 1991. Negative affectivity as the underlying cause of correlations between stressors and strains. Fournal of Applied Psychology, 76, 398-407.

De Vaus, D., Wells, Y., Kendig, H. and Quine, S. 2007. Does gradual retirement have better outcomes than abrupt retirement? Results from an Australian panel study. Ageing E Society, 27, 5, 667-82.

Diener, E., Emmons, R. A., Larsen, R. J. and Griffen, S. I985. The satisfaction with life scale. Fournal of Personality Assessment, 49, $\mathrm{I}_{7} \mathrm{I}-5$.

Ekerdt, D. J. and DeViney, S. I993. Evidence for a preretirement process among older male workers. Fournals of Gerontology, 48, 35-43.

Gilleard, C. and Higgs, P. 200o. Cultures of Ageing: Self, Citizen and the Body. Prentice Hall, London.

Glass, T. A., Mendes de Leon, C. F., Bassuk, S. S. and Berkman, L. F. 20o6. Social engagement and depressive symptoms in late life: Longitudinal findings. Fournal of Aging and Health, 18, 604-28.

Glass, T. A., Mendes de Leon, C., Marottoli, R. A. and Berkmam, L. F. I999. Population based study of social and productive activities as predicators of survival among elderly Americans. British Medical Fournal, 319, 478-83.

Gouldner, A. W. I96o. The norm of reciprocity. American Sociological Review, 25, I6I-78.

Government Actuaries Department 2002. Populations Projections: Population of Great Britain in Five-year Age Bands (http://www.gad.gov.uk/Population/2002/gb).

Harewood, R. H., Pound, P. and Ebrahim, S. 200o. Determinants of social engagement in older men. Psychololgy, Health and Medicine, 5, I, 75-85.

Hill, L., Edwards, G., Myers, L., Saeed, Z., Dunn, S. and Fisher, K. 1999. Social Focus on Older People. Stationery Office, London.

Hirst, M. 2005. Carer distress: a prospective, population-based study. Social Science and Medicine, 6r , 3, 697-708.

Hoge, T. and Bussing, A. 2004. The impact of sense of coherence and negative affectivity on the work stressor-strain relationship. Fournal of Occupational Health Psychology, 9, 3, 195-205.

Hyde, M., Ferrie, J., Higgs, P., Mein, G. and Nazroo, J. 2004. The effects of pre-retirement factors and retirement route on circumstances in retirement: findings from the Whitehall II study. Ageing \& Society, 24, 279-96.

Hyde, M., Wiggins, R. D., Higgs, P. and Blane, D. B. 2003. A measure of quality of life in early old age: the theory, development and properties of a needs satisfaction model (CASP-r9). Aging and Mental Health, 7, I86-94.

Kikuzawa, S. 2006. Multiple roles and mental health in cross-cultural perspective: The elderly in the United States and Japan. Fournal of Health and Social Behavior, 47, 62-76.

Kivimaki, M., Leino-Arjas, P., Luukonen, R., Riihimaki, H., Batear, J. and Kirjonen, J. 2002. Work stress and risk of cardiovascular mortality: Prospective cohort study of industrial employees. British Medical Fournal, 325, 857-63.

Kuper, H., Singh-Manoux, A., Siegrist, J. and Marmot, M. 2002. When reciprocity fails: Effort-reward imbalance in relation to coronary heart disease and health functioning with the Whitehall II study. Occupational and Environmental Medicine, 59, 777-84. 
Laczko, F. and Phillipson, C. I991. Changing Work and Retirement. Open University Press, Buckingham, UK.

Laslett, P. 1996. A Fresh Map of Modern Life. Macmillan, London.

Lennartsson, C. and Silverstein, M. 200r. Does engagement with life enhance survival of elderly people in Sweden? The role of social and leisure activities. Foumals of Gerontology, B Series: Psychological Sciences and Social Sciences, 56, 6, S335-42.

Luoh, M.-C. and Herzog, A. R. 2002. Individual consequences of volunteer and paid work in old age: health and mortality. Fournal of Health and Social Behavior, 43, 490-509.

Lynch, K. 2007. Love labour as a distinct and non-commodifiable form of care labour. Sociological Review, 55, 3, 550-70.

Marmot, M., Siegrist, J. and Theorell, T. 2006. Health and the psychosocial environment at work. In Marmot, M and Wilkinson, R. (eds), Social Determinants of Health. Second edition, Oxford University Press, Oxford, 97-130.

Meier, S. and Stutzer, A. 2008. Is volunteering rewarding in itself? Economica, 75, 39-59.

Mein, G., Martikainen, P., Stansfeld, S. A., Brunner, E. J., Fuhrer, R. and Marmot, M. 200o. Predictors of early retirement in British civil servants. Age and Ageing, 29, 529-36.

Mendes de Leon, C. F., Gold, D. T., Glass, T. A., Kaplan, L. and George, L. K. 200 . Disability as a function of social networks and support in elderly African Americans and whites: the Duke EPESE 1986-1992. Journal of Gerontology B Series: Psycholological Sciences and Social Sciences, 56, 3, Si79-9o.

Mendes de Leon, C. F., Glass, T. A. and Berkman, L. F. 2003. Social engagement and disability in a community population of older adults: the New Haven EPESE. American Journal of Epidemiology, $\mathbf{1 5 7 , 7 , 6 3 3 - 4 2 . ~}$

Menec, V.H. 2003. The relation between everyday activities and successful aging: a 6-year longitudinal study. Fournals of Gerontology B Series: Psychological Sciences and Social Sciences, 58, I, 74-82.

Moen, P. I996. A life course perspective on retirement, gender, and wellbeing. Fournal of Occupational Health Psychology, I, 2, I3 I-44.

Morrow-Howell, N., Hinterlong, J., Rozario, P. A. and Tang, F. 2003. Effects of volunteering on the wellbeing of older adults. Fournals of Gerontology Series B: Psychological Sciences and Social Sciences, 58, Si37-45.

Musick, M. A., Herzog, A. R. and House, J. S. i999. Volunteering and mortality among older adults: findings from a national sample. Journals of Gerontology Series B: Psychological Sciences and Social Sciences, 54, Si73-80.

Niedhammer, I., Tek, M. L., Starke, D. and Siegrist, J. 2004. Effort-reward imbalance model and self-reported health: cross-sectional and prospective findings from the GAZEL cohort. Social Science and Medicine, 58, I53 I-4I.

Parry, J. and Taylor, R. F. 2007. Orientation, opportunity and autonomy: why people work after state pension age in three areas of England. Ageing \& Society, 27, 4, 579-98.

Phillipson, C. I99o. The sociology of retirement. In Bond, J. and Coleman, P. (eds), Ageing in Society: An Introduction to Social Gerontology. Sage, London, I44-6o.

Pikart, H., Bobak, M., Pajak, A., Malyutina, S., Kubinova, R. and Topor, R. 2004. Psychosocial factors at work and depression in three countries of Central and Eastern Europe. Social Science and Medicine, 58, I475-82.

Piliavin, J. and Siegl, E. 2007. Health benefits of volunteering in the Wisconsin Longitudinal Study. Fournal of Health and Social Behavior, 48, 4, 450-64.

Santed, M. A., Sandin, B., Charot, P., Olmedo, M. and Garcia-Campayo, J. 2003. The role of negative and positive affectivity on perceived stress-subjective health relationships. Acta Neropsychiatrica, I5, 4, I99-2i6.

Schnall, P. L., Belkic, K., Landsbergis, P. and Baker, D. 200o. The workplace and cardiovascular disease. Occupation Medicine: State of the Art Reviews, I5, I-334. 
Siegrist, J. 1996. Adverse health effects of high-effort/low-reward conditions. Fournal of Occupational Health Psychology, I, I, 27-4I.

Siegrist, J. 2005. Social reciprocity and health: new scientific evidence and policy implications. Psychoneuroendocrinology, 3o, 1033-38.

Siegrist, J. and Marmot, M. 2004. Health inequalities and the psychosocial environment: two scientific challenges. Social Science and Medicine, 58, i463-73.

Siegrist, J., von dem Knesebeck, O. and Evan Pollack, C. 2004. Social productivity and wellbeing of older people: a sociological exploration. Social Theory and Health, 2, I-I7.

Siegrist, J., Wahrendorf, M., von dem Knesebeck, O., Jurges, H. and Borsch-Supan, A. 2007. Quality of work, wellbeing, and intended early retirement of older employees: baseline results from the SHARE Study. European Fournal of Public Health, I 7, I, 62-8.

Spector, P. E., Chen, P. Y. and O'Connell, B. J. 2000. A longitudinal study of relations between job stressors and job strains while controlling for prior negative affectivity and strains. Fournal of Applied Psychology, 85, 2, 21 I-18.

Stansfeld, S. A., Bosma, H., Hemingway, H. and Marmot, M. I998. Psychosocial work characteristics and social support as predictors of $\mathrm{SF}_{-3} 6$ health functioning: the Whitehall II study. Psychosomatic Medicine, 6o, 247-55.

Stansfeld, S. A., Fuhrer, R., Shipley, M. J. and Marmot, M. G. I999. Work characteristics predict psychiatric disorder: prospective results from the Whitehall II Study. Occupational and Environmental Medicine, 56, 302-7.

Steffick, D. E. 200o. Documentation of Affective Functioning Measures in the Health and Retirement Study. HRS Health Working Group, University of Michigan, Ann Arbor, Michigan.

Thoits, P. A. and Hewitt, L. N. 200I. Volunteer work and wellbeing. Fournal of Health and Social Behavior, 42, II5-3I.

Thorensen, C., Kaplan, S. A., Barsky, A. P., Warren, C. R. and de Chermont, K. 2003. The affective underpinnings of job perceptions and attitudies: a meta-analytic review and integration. Psychological Bulletin, I 29, 6, 914-45.

Townsend, P. I98I. The structured dependency of the elderly: a creation of social policy in the twentieth century. Ageing \& Society, I, I, 5-18.

Van Willigen, M. 2000. Differential benefits of volunteering across the life course. Fournals of Gerontology B Series: Psychological Sciences and Social Sciences, 55, 5, S308-18.

Wahrendorf, M., von dem Knesebeck, O. and Siegrist, J. 2006. Social productivity and wellbeing of older people: baseline results from the SHARE study. European Fournal of Ageing, 3, I, 67-73.

Address for correspondence:

Accepted 26 November 2008

Anne McMunn, Department of Epidemiology and Public Health, University College London, I-I9 Torrington Place, London WGiE 6BT, UK.

E-mail: a.mcmunn@ucl.ac.uk 